\title{
Clinical and histopathological features of fatal cases with dengue and chikungunya virus co-infection in Colombia, 2014 to 2015
}

M Mercado ${ }^{1}$, J Acosta-Reyes ${ }^{2}$, E Parra 3, L Pardo ${ }^{3}$, A Rico ${ }^{3}$, A Campo 4 , E Navarro 2 , D Viasus 5

1. Division of Research in Public Health, National Institute of Health of Colombia, Bogota, Colombia

2. Faculty of Public Health, Division of Health Sciences, Universidad del Norte and Hospital Universidad del Norte, Barranquilla, Colombia

3. Direction of Public Health Networks, Virology and Pathology Laboratories, National Institute of Health of Colombia, Bogotá, Colombia

4. Division of Surveillance in Public Health, National Institute of Health of Colombia, Bogota, Colombia

5. Faculty of Medicine, Division of Health Sciences, Universidad del Norte and Hospital Universidad del Norte, Barranquilla, Colombia

Correspondence: Diego Viasus (dviasus@uninorte.edu.co)

Citation style for this article:

Mercado M, Acosta-Reyes J, Parra E, Pardo L, Rico A, Campo A, Navarro E, Viasus D. Clinical and histopathological features of fatal cases with dengue and

chikungunya virus co-infection in Colombia, 2014 to 2015. Euro Surveill. 2016;21(22):pii=30244. DOI: http://dx.doi.org/10.2807/1560-7917.ES.2016.21.22.30244

Article submitted on 28 October 2015 / accepted on 17 March 2016 / published on 02 June 2016

We report clinical features and histopathological findings in fatal cases with dengue (DENV) and chikungunya (CHIKV) co-infection identified at the Colombian National Institute of Health between September 2014 and October 2015. Seven such cases were documented. Dengue serotype 2 virus was identified in six cases. All patients were adults and comorbidities were present in four. Fever, arthralgia or myalgia was present in all cases. The frequency of rash, haemorrhage, oedema, and gastrointestinal symptoms was variable. Laboratory findings such as thrombocytopenia, renal failure, and leukocyte count were also inconsistent between cases. Post-mortem tissue examination documented focal hepatocellular coagulative necrosis in three cases, incipient acute pericarditis in one and tubulointerstitial nephritis in one. This study provides evidence of mortality in patients with DENV and CHIKV co-infection. Fatal cases were characterised by variable clinical and laboratory features. Evaluation of histopathology of autopsy tissues provided evidence of the pathological consequences of the disease.

\section{Introduction}

Arboviral diseases such as dengue and chikungunya infection are among the leading infectious health problems in the world today $[1,2]$. The majority of dengue virus (DENV) infections occur in Asia, the Pacific, South and Central America and the Caribbean, where they are considered a public health problem [3]. The chikungunya virus (CHIKV) was first isolated in Tanzania in 1953 and has repeatedly been identified in western, central and southern Africa and in many parts of Asia. Imported cases among tourists have been identified in several European countries and the United States [4].
The infection recently appeared in the Americas [5], when autochthonous transmission of the CHIKV was identified in St Martin in 2013. Since then, CHIKV has spread to 33 countries and territories in the Caribbean, South, Central and North America with nearly 2 million cases identified [6].

Patients with DENV or CHIKV infection generally present with a self-limited febrile disease. However, DENV infection has several complications, mainly dengue shock syndrome and haemorrhagic manifestations. CHIKV infection is not regarded as a life-threatening disease $[7,8]$, but mortality due to CHIKV was reported during the Reunion Island outbreak in 2006 [9]. Although the overall proportion of atypical and severe cases was low, mortality in these cases was high. In areas where both viruses co-circulate, both can be transmitted to the same human host and pose a challenge for medical diagnosis. DENV and CHIKV co-infection has been reported in several studies in a non-negligible proportion of cases [10-12]. However, fatalities in patients with DENV and CHIKV co-infection have been rare to date. Mortality has been reported in only one case without other specific information [13].

In this paper we present the clinical and laboratory findings recorded in cases of fatal DENV and CHIKV co-infection occurring in Colombia and correlate them with the histopathological features of post-mortem tissue biopsy.

\section{Methods}

In accordance with the procedures established in Colombia for the reporting, collection and analysis 


\section{FIGURE}

Histopathological findings of fatal cases of dengue and chikungunya virus co-infection $(\mathrm{n}=3)$

A. Kidney

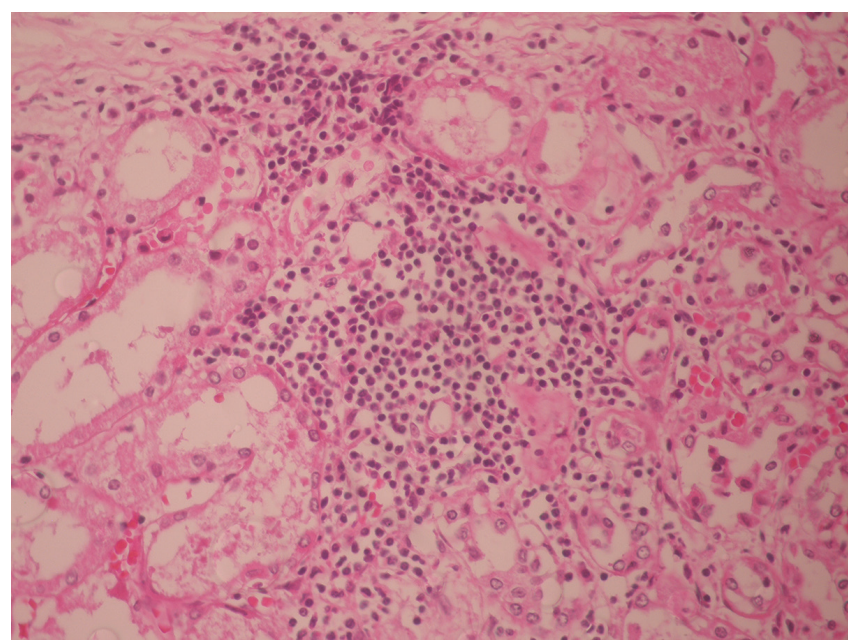

B. Liver

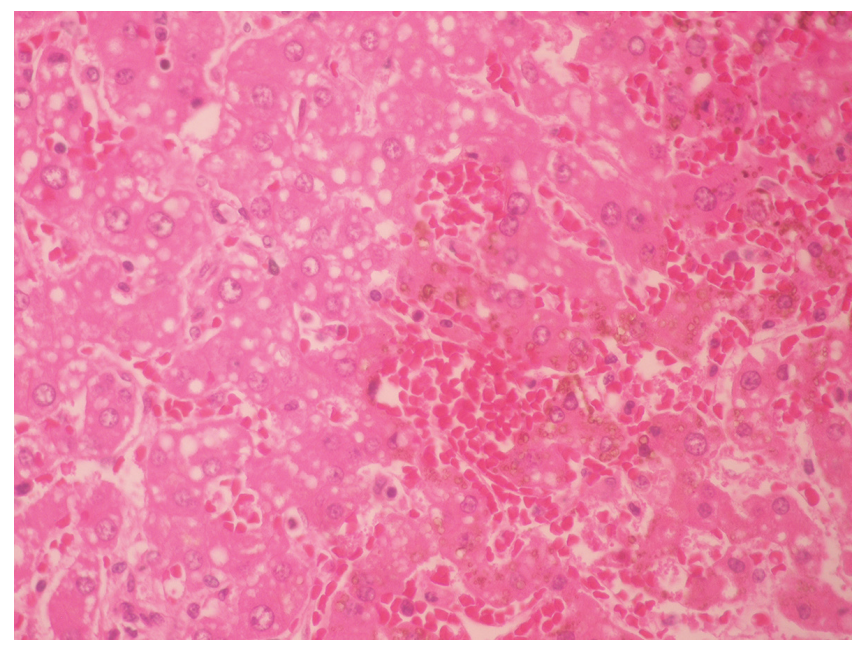

C. Heart

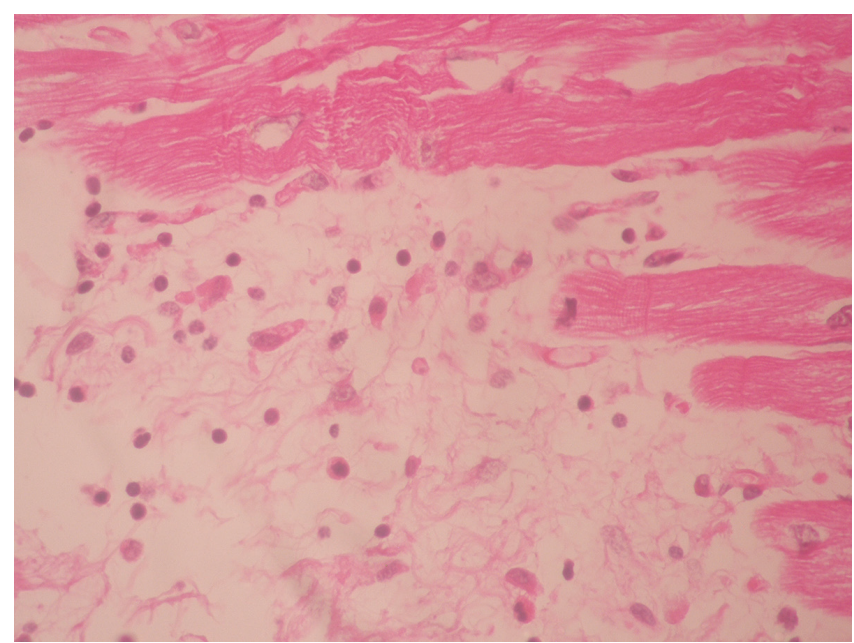

of clinical data, patients with dengue and chikungunya fever are notifiable and undergo continuous and systematic monitoring. The cases are reported to the National System for Public Health Surveillance (SIVIGILA), which collects all the clinical information of cases of public health interest from around the country. Cases with initial diagnoses of 'probable' are then confirmed by the National Institute of Health through laboratory tests or histopathological findings and clinical features [14-16]. The guidelines of the Ministry of Health and Social Protection stipulate that post-mortem biopsies are required for fatal events due to DENV or CHIKV. The case definitions for dengue and chikungunya fatal cases are described elsewhere [14-16]. A fatal case of dengue is defined as a patient with severe dengue with laboratory-confirmed diagnosis by antiDENV IgM, viral isolation or PCR (PCR), and compatible histopathological findings. A fatal case of chikungunya is defined as a patient with an acute illness consistent with the disease who developed severe or atypical clinical manifestations, and with laboratory-confirmed diagnosis by anti-CHIKV IgM, viral isolation or PCR.

This retrospective study included all fatal cases that occurred from September 2014 through October 2015 reported to SIVIGILA and that were laboratory-confirmed for DENV and CHIKV co-infection by the National Institute of Health. We collected detailed, serial clinical findings including history, physical examination, and haematological, biochemical, radiological and virological results, and entered them into a predesigned database. Histopathological examinations were performed when tissue autopsy was available.

Serum samples obtained at hospital admission and tissues from autopsies were processed in the Arbovirus Laboratory at the National Institute of Health. For the determination of anti-DENV IgM in serum, a commercial capture ELISA kit was used. DENV and CHIKV were identified by PCR on serum or tissue. On tissue sections, cell lysis was performed and the viral RNA was extracted using a commercial QIAamp viral RNA mini kit. DENV was identified and characterised by conventional PCR as described elsewhere [17]. The CHIKV identification test was conducted with qRT-PCR protocol according to Lanciotti et al. [18].

Histopathological features were reported for four cases. Formalin-fixed tissues from fatal cases were processed, embedded in paraffin, and cut in $5 \mu \mathrm{m} \mathrm{sec-}$ tions. Histopathological changes were examined on haematoxylin- and eosin-stained tissue sections under light microscopy.

Haematoxylin- and eosin-stained tissue sections under light microscopy (40X).

(A) Kidney (Case 6): Glomerular oedema, tubular structure with hyaline casts, and small focus of tubulointerstitial nephritis.

(B) Liver (Case 5): Individual areas of coagulative hepatocellular necrosis and mild infiltrate of mixed inflammatory cells.

(C) Heart (Case 7): Epicardium with mild mononuclear inflammatory infiltrate compatible with acute pericarditis, and myocardial tissue without inflammatory infiltrate or remodelling areas. 


\section{Results}

During the study period, seven fatal cases of DENV and CHIKV co-infection were identified among 58 CHIKV deaths documented by the National Institute of Health. Clinical features were reported for all cases, but in one patient, laboratory findings were not available (Table). Co-infection was diagnosed by positive CHIKV and DENV PCR on post-mortem tissue in Cases 2, 3 and 6 (CHIKV PCR was also positive in serum in Cases 2 and 6), by positive CHIKV and DENV PCR on serum in Cases 1, 5 and 7 (DENV PCR was also positive in post-mortem tissue in Case 7), and by positive CHIKV PCR on serum and positive DENV PCR on post-mortem tissue in Case 4. The cycle threshold values for CHIKV PCR were $16.8-$ 32.5. Anti-DENV IgM in serum was analysed in two cases and the results were negative. Dengue serotype 2 virus (DENV-2) was identified in six cases and DENV-3 in the remaining case.

All patients were adults (four were older than 60 years) and four were female. One case was a pregnant woman in the 37th week of gestation. Two days after hospital admission, this patient gave birth to a live child with normal physical examination. Four of the seven cases presented comorbidities. Hypertension was the most frequent underlying disease (three cases) and one case had hypothyroidism. Time from symptom onset to hospital admission was shorter than four days in all cases (range: $1-4$ days). Although all patients reported to have had fever at home, axillary temperature was high $\left(38^{\circ} \mathrm{C}\right)$ in only two cases at hospital admission. Arthralgia or myalgia at hospital admission was reported for all patients. Haemorrhagic manifestations were documented in four cases (mucosal bleeding in three cases and haemorrhagic stroke that occurred six days after hospital admission in one case) and oedema of the lower limb in two patients. Two cases reported gastrointestinal symptoms (diarrhoea, nausea or vomiting). However, no ascites or pleural effusion were reported.

As regards laboratory findings at admission (Table), one case had leucopenia $\left(<4 \times 10^{9} / \mathrm{L}\right)$ and three had leukocytosis $\left(>12 \times 10^{9} / \mathrm{L}\right)$. Haematocrit and haemoglobin index were below 3.2 in all cases. Thrombocytopenia $\left(<100 \times 10^{9} / \mathrm{L}\right)$ was documented in two cases at admission, and Cases 2, 4 and 7 developed the condition during hospitalisation (range: 22 to $55 \times 10^{9} / \mathrm{L}$ ). Renal failure (creatinine $>2 \mathrm{mg} / \mathrm{dL}$ ) was reported in three patients (Case 1 developed this complication after admission). Four patients presented elevated transaminases, mainly aspartate aminotransferase (>34 U/L), but their values were not higher than 1,000 U/L.

Six patients died within three days of hospital admission, and the last died after 16 days (Case 4). Causes of mortality were multiorgan dysfunction syndrome, shock in one case, and sepsis associated with nosocomial infection in the pregnant woman (Case 4). For Case 4, blood and respiratory cultures yielded Acinetobacter baumannii.
Post-mortem tissue examination was performed for four cases. The histopathological findings in Case 4 were related with septic shock. The other three cases (Cases 5, 6 and 7) presented coagulative hepatocellular necrosis; Case 5 presented incipient acute pericarditis and Case 6 tubulointerstitial nephritis (Figure). Mild oedema was observed in the lung of all four patients but there was no evidence of inflammation. Similarly, no inflammatory infiltrate was found in the myocardial or brain tissues.

\section{Discussion}

Our data provide evidence of mortality associated with DENV and CHIKV co-infection. DENV-2 was the predominant serotype in our study. The clinical picture of DENV and CHIKV infection regularly presented fever, arthralgia or myalgia, and rash. Other clinical and laboratory characteristics presented variations. Histopathological examinations were consistent with arbovirus infection.

Some studies using serological assays or PCR tests have reported that co-infection of DENV and CHIKV is not uncommon $[10-13,19]$. In a study performed in India in 2010, Taraphdar et al. [10] found that 68 (12.4\%) of 550 blood samples of febrile cases had IgM antibodies against both DENV and CHIKV. In another study, $16(2.8 \%)$ of 1,502 suspected cases of CHIKV infection were confirmed to be DENV and CHIKV co-infections in the Caribbean island of St Martin [11]. Moreover, a study carried out in Gabon documented 37 co-infected patients with DENV serotype 2 and CHIKV among 4,287 febrile patients (1,567 with CHIKV infection) [12]. Importantly, in all previous studies, dual infected patients were not severely ill and recovered quickly. Mortality has been reported in only one case without other specific information [13]. However, these observations should be interpreted with caution in view of the limited number of clinical and biological investigations available [19].

Moreover, DENV or CHIKV may be underdiagnosed in areas where both viruses circulate. Multiple infections in a single patient may change the spectrum of clinical manifestations or overlapping clinical symptoms and thus complicate the diagnosis $[10,20,21]$. In addition, the recent emergency of Zika virus has led to the co-circulation of these three arboviruses in many countries and there is the possibility of co-infections [22].

In our study, we found that the main classical clinical manifestations associated with DENV or CHIKV infection [23] were present at hospital admission, but the incidence of other manifestations such as haemorrhage, oedema and gastrointestinal symptoms tended to vary. Other laboratory findings such as thrombocytopenia, renal failure, and leukocyte count were also inconsistent among our cases. Moreover, none of our cases had systemic vascular leak syndrome (haemoconcentration, pleural effusion and ascites). In previous studies, thrombocytopenia and bleeding were rare complications in patients mono-infected with CHIKV, 
Clinical features and laboratory findings in fatal cases with dengue and chikungunya virus co-infection $(n=7)$

\begin{tabular}{|c|c|c|c|c|c|c|c|}
\hline & Case 1 & Case 2 & Case 3 & Case 4 & Case 5 & Case 6 & Case 7 \\
\hline \multicolumn{8}{|l|}{ Clinical features } \\
\hline Age (> 6o years-old) & Yes & Yes & Yes & No & No & Yes & No \\
\hline Comorbidities & Hypertension & Hypertension & Hypothyroidism & Pregnancy & None & Hypertension & None \\
\hline Time from symptom onset (days) & 3 & 3 & 4 & 1 & 3 & 2 & 3 \\
\hline Fever & Yes & Yes & Yes & Yes & Yes & Yes & Yes \\
\hline Arthralgia & Yes & Yes & Yes & Yes & Yes & Yes & Yes \\
\hline Rash & Yes & Yes & Yes & Yes & No & No & Yes \\
\hline $\begin{array}{l}\text { Haemorrhagic } \\
\text { manifestations }\end{array}$ & No & Petechiae & $\begin{array}{l}\text { Haemorrhagic } \\
\text { blisters }\end{array}$ & $\begin{array}{l}\text { Haemorrhagic } \\
\text { stroke }\end{array}$ & No & $\begin{array}{c}\text { Upper } \\
\text { gastrointestinal } \\
\text { bleeding }\end{array}$ & No \\
\hline Oedema & Yes & No & Yes & No & No & No & No \\
\hline $\begin{array}{l}\text { Time from admission } \\
\text { to mortality (days) }\end{array}$ & 3 & 1 & 2 & 16 & 1 & 1 & 2 \\
\hline \multicolumn{8}{|l|}{ Laboratory findings at admission } \\
\hline Haemoglobin (g/dL) & 15.4 & 13.9 & 19.2 & 14 & 14.6 & NA & 11.5 \\
\hline Haematocrit (\%) & 44 & 42 & 58 & 42 & 44 & NA & $35 \cdot 7$ \\
\hline Total white cells $\left(10^{9} / \mathrm{L}\right)$ & 12.6 & 15.1 & 26.7 & 7.4 & 5.4 & NA & 3.1 \\
\hline Platelets (10\%/L) & 210,000 & 161,000 & 60,000 & 120,000 & 99,000 & NA & 151.000 \\
\hline Creatinine $(\mathrm{mg} / \mathrm{dL})$ & 0.98 & 5.5 & 2.4 & 0.49 & 0.65 & NA & 0.67 \\
\hline $\begin{array}{l}\text { Aspartate } \\
\text { aminotransferase }(\mathrm{U} / \mathrm{L})\end{array}$ & NA & 419 & 252 & 13 & 72.4 & NA & 186 \\
\hline $\begin{array}{l}\text { Alanine } \\
\text { aminotransferase }(\mathrm{U} / \mathrm{L})\end{array}$ & NA & 69 & 37 & 8 & 50.2 & NA & 137 \\
\hline
\end{tabular}

NA: not available.

Normal ranges: Haemoglobin: $12-17 \mathrm{~g} / \mathrm{dL}$; haematocrit: $40-50 \%$; platelets: $150-600 \times 10^{9} / \mathrm{L}$; total white cells: 4-12 $\times 10^{9} / \mathrm{L}$; creatinine: $0.75-1.2 \mathrm{mg} / \mathrm{dl}$; aspartate aminotransferase $10-34 \mathrm{U} / \mathrm{L}$; alanine aminotransferase: 5-59 U/L.

but were more frequent in patients infected with DENV. Similarly, recent studies have reported renal failure in patients who died of CHIKV infection. Finally, leukopenia has frequently been described in patients with DENV, but leukocytosis has commonly been documented in fatal cases of CHIKV $[21,24,25]$. These data emphasise the need for a multidimensional diagnostic approach in these clinical situations. In countries where both diseases are endemic, the differential diagnosis between severe DENV and CHIKV infections or co-infection may be a challenge.

The critical period of development of complications or mortality in patients with DENV infection is between four and six days after symptom onset [26], and from four to eight days in patients with CHIKV infection $[24,25]$. Similar time frames were documented in the present study of co-infected DENV and CHIKV fatal cases. Moreover, the assessment of histopathology of autopsy tissues in the present study provided evidence of the pathological consequences of the disease. It is important to note that in one of our cases, mortality did not seem to be directly related to virus infection: this patient died several days after hospital admission due to a sepsis associated with nosocomial infection, and the histopathological findings were compatible with a septic process. Conversely, in the other six cases, laboratory data coincided with those found in histopathological studies. Renal failure with high creatinine values and elevated transaminases concurred with the pathology findings of tubular interstitial nephritis or tubular necrosis and hepatocellular necrosis. Moreover, the histopathological results in the liver coincided with those described in fatal DENV infections [27]. However, these liver pathology results have also been found in fatal cases of CHIV mono-infection in Colombia (data not shown). Interestingly, although no histopathological evidence of myocarditis or encephalitis was observed in any of the case-patients in the present study, these complications have been reported previously in patients with DENV or CHIKV infection $[14,15]$. A study has documented DENV in cerebrospinal fluid, in macrophage-like cells and neurons in the central nervous system [28]. Similarly, experimental infection in animal models has documented the capacity of CHIKV to infect leptomeningeal tissue and glial cells [29].

Most of our cases were co-infected with DENV serotype 2. Along with serotypes 1,3 and 4 , this serotype has been associated with CHIKV co-infection in other studies $[11-13,19,30,31]$. Moreover, the genome sequence of the CHIKV strain circulating in America was shows that it belongs to the Asian genotype, suggesting Asia as 
the probable origin of the circulating virus $[32,33]$. In Colombia, the National Health Institute reported similar data. By contrast, lethal cases of CHIKV infection have previously been associated with infections by the east/central/south African (ECSA) genotype, which was responsible for the large epidemics on islands in the Indian Ocean and the Indian subcontinent. However, in a recent study performed in Bahia State in east-central Brazil, the ECSA genotype was also found [34].

It is difficult to establish the possible effect of both CHIKV and DENV on mortality in our cases. A previous study documented that CHIKV and DENV serotype 2 loads in co-infected patients were always significantly lower than those in DENV and CHIKV mono-infected patients. However, the co-infected patients might have high loads of CHIKV or DENV, or both [12]. The authors of that study suggest that interaction between viruses or the timing of a bite from an infected mosquito could explain these findings. Unfortunately, in our study we did not analyse viral load and immune response. Moreover, it has been documented that when shock sets in, dengue virus is no longer detectable in blood, and it has therefore been suggested that the host response should play a key role in pathogenesis. But there is evidence suggesting that DENV replication may occur in some organs, while viraemia is no longer detectable [28]. It is interesting to note that in the present study, time from symptom onset to mortality was shorter than six days in most cases (except Case 4) and RT-PCR on serum (6 cases) or post-mortem tissues (5 cases) was positive while the serological results were negative, suggesting viraemia or viral replication in tissues.

There are several limitations to our study. The detection of suspected cases of mortality due to DENV or CHIKV infection depends on the reports made by physicians in different areas of the country. In addition, serological tests and PCR for DENV and CHIKV are not available in most Colombian hospitals. Therefore, it is likely that certain cases were not detected. Moreover, anti-DENV and anti-CHIKV IgM were not determined in all cases. However, it can be expected that serology would have been negative because most of the cases had an acute infection ( $\leq 6$ days since symptom onset). Finally, postmortem examination was not performed in one case and immunohistochemical studies were not done.

\section{Conclusion}

Our data provide evidence of mortality associated with DENV and CHIKV co-infection. Post-mortem histopathological findings were consistent with arbovirus infection. The variations in the clinical and laboratory findings make an accurate diagnosis difficult and highlight the need for sensitive and rapid tests. It is important to differentiate between them as their management, especially for dengue, is different. Prospective studies evaluating the immune response and virological aspects of co-infection are now required.
Acknowledgements

This work was supported by Universidad del Norte (PEo031/2014DViasus).

The funding sources had no role in the study design, in the collection, analysis and interpretation of data; in the writing of the manuscript; or in the decision to submit the manuscript for publication.

This study was approved by the Ethics Committee of the Universidad del Norte in Barranquilla, Colombia.

\section{Conflict of interest}

All authors have no conflicts of interest to disclose.

\section{Authors' contributions}

All authors had full access to the study data. Study concept and design: M.M, J.A, and D.V. Collection, analysis and interpretation data: E.P, L.P, A.C, and A.R. Drafting of the manuscript: M.M, E.G, and D.V. Critical revision of the manuscript for important intellectual content: J.A, E.P; L.P, and A.C. Obtained funding: D,V. All authors have seen and approved the final manuscript.

\section{References}

1. Gubler DJ. The global emergence/resurgence of arboviral diseases as public health problems.Arch Med Res. 2002;33(4):330-42. DOI: 10.1016/S0188-4409(02)00378-8 PMID: 12234522

2. Weaver SC, Reisen WK. Present and future arboviral threats.Antiviral Res. 2010;85(2):328-45. DOI: 10.1016/j. antiviral.2009.10.008 PMID: 19857523

3. Murray NE, Quam MB, Wilder-Smith A. Epidemiology of dengue: past, present and future prospects.Clin Epidemiol. 2013;5:299-309.PMID: 23990732

4. Thiberville SD, Moyen N, Dupuis-Maguiraga L, Nougairede A, Gould EA, Roques P, et al. Chikungunya fever: epidemiology, clinical syndrome, pathogenesis and therapy. Antiviral Res. 2013;99(3):345-70. DOI: 10.1016/j.antiviral.2013.06.009 PMID: 23811281

5. Weaver SC. Arrival of chikungunya virus in the new world: prospects for spread and impact on public health.PLoS Negl Trop Dis. 2014;8(6):e2921. DOI: 10.1371/journal.pntd.0002921 PMID: 24967777

6. Chikungunya disease: gaps and opportunities in public health and research in the Americas. Wkly Epidemiol Rec. 2015;90(42):571-6.PMID: 26477060

7. Simmons CP, Farrar JJ, van Vinh Chau N, Wills B. Dengue.N Engl J Med. 2012;366(15):1423-32. DOI: 10.1056/NEJMra1110265 PMID: 22494122

8. Pialoux G, Gaüzère BA, Jauréguiberry $S$, Strobel $M$. Chikungunya, an epidemic arbovirosis. Lancet Infect Dis. 2007;7(5):319-27. DOI: 10.1016/S1473-3099(07)70107-X PMID: 17448935

9. Economopoulou A, Dominguez M, Helynck B, Sissoko D, Wichmann 0, Quenel P, et al. Atypical Chikungunya virus infections: clinical manifestations, mortality and risk factors for severe disease during the 2005-2006 outbreak on Réunion. Epidemiol Infect. 2009;137(4):534-41. DOI: 10.1017/ So950268808001167 PMID: 18694529

10. Taraphdar D, Sarkar A, Mukhopadhyay BB, Chatterjee S. A comparative study of clinical features between monotypic and dual infection cases with Chikungunya virus and dengue virus in West Bengal, India.Am J Trop Med Hyg. 2012;86(4):720-3. DOI: 10.4269/ajtmh.2012.11-0704 PMID: 22492160

11. Omarjee R, Prat C, Flusin O, Boucau S, Tenebray B, Merle O, et al. Importance of case definition to monitor ongoing outbreak of chikungunya virus on a background of actively circulating dengue virus, St Martin, December 2013 to January 2014. Euro Surveill. 2014;19(13):20753. DOI: 10.2807/1560-7917. ES2014.19.13.20753 PMID: 24721537

12. Caron M, Paupy C, Grard G, Becquart P, Mombo I, Nso $\mathrm{BB}$, et al. Recent introduction and rapid dissemination of Chikungunya virus and Dengue virus serotype 2 associated 
with human and mosquito coinfections in Gabon, central Africa. Clin Infect Dis. 2012;55(6):e45-53. DOI: 10.1093/cid/ cis530 PMID: 22670036

13. Chahar HS, Bharaj P, Dar L, Guleria R, Kabra SK, Broor S. Coinfections with chikungunya virus and dengue virus in Delhi, India.Emerg Infect Dis. 2009;15(7):1077-80. DOI: 10.3201/ eid1507.080638 PMID: 19624923

14. De la Hoz F, Martínez-Duran ME, Pacheco-García OE, QuijadaBonilla H. Protocolo de vigilancia en salud pública. Dengue. [Public health surveillance protocol. Dengue]. Bogotá: Instituto Nacional de Salud; 2014. Spanish. Available from: http://www. ins.gov.co/lineas-de-accion/Subdireccion-Vigilancia/sivigila/ Protocolos\%20SIVIGILA/PRO\%20Dengue.pdf

15. Protocolo de vigilancia en salud pública. Chikunguña. [Public health surveillance protocol. Chikungunya]. Bogotá: Instituto Nacional de Salud; 2015. Spanish. Available from: http://www. ins.gov.co/lineas-de-accion/Subdireccion-Vigilancia/sivigila/ Protocolos\%20SIVIGILA/PRO\%20Chikungunya.pdf

16. Gaviria-Uribe A, Ruíz-Gómez F, Burgos-Bernal G, OspinaMartínez ML, De Jesús-Osorio Saldarriaga E, MuñózRamírez MA, et al. Propuesta metodológica para el análisis y clasificación de muertes atribuibles a la enfermedad por virus Chikungunya. [Proposed method for the analysis and classification of deaths attributable to the disease caused by chikungunya virus]. Bogotá: Ministerio de Salud y Protección Social de Colombia; 2015. Instituto Nacional de Salud. Spanish. Available from: https://www.minsalud.gov. co/sites/rid/Lists/BibliotecaDigital/RIDE/VS/ED/Propuestametodologica-analisis-clasificacion-muertes-Chikungunya.pdf

17. Usme-Ciro JA, Gómez-Castañeda AM, Gallego-Gómez JC. Molecular detection and typing of dengue virus by RT-PCR and nested PCR using degenerated oligonucleotides.Salud Uninorte. 2012;28(1):1-15.

18. Lanciotti RS, Kosoy OL, Laven JJ, Panella AJ, Velez JO, Lambert $\mathrm{AJ}$, et al. Chikungunya virus in US travelers returning from India, 2006. Emerg Infect Dis. 2007;13(5):764-7. DOI: 10.3201/ eid1305.070015 PMID: 17553261

19. Leroy EM, Nkoghe D, Ollomo B, Nze-Nkogue C, Becquart P, Grard G, et al. Concurrent chikungunya and dengue virus infections during simultaneous outbreaks, Gabon, 2007. Emerg Infect Dis. 2009;15(4):591-3. DOI: 10.3201/eid1504.080664 PMID: 19331740

20. Raut CG, Rao NM, Sinha DP, Hanumaiah H, Manjunatha MJ. Chikungunya, dengue, and malaria co-infection after travel to Nigeria, India.Emerg Infect Dis. 2015;21(5):908-9. DOI: 10.3201/eid2105.141804 PMID: 25898147

21. Nkoghe D, Kassa RF, Bisvigou U, Caron M, Grard G, Leroy EM. No clinical or biological difference between Chikungunya and Dengue Fever during the 2010 Gabonese outbreak.Infect Dis Rep. 2012;4(1):e5. DOI: 10.4081/idr.2012.e5 PMID: 24470935

22. Villamil-Gómez WE, González-Camargo 0, Rodriguez-Ayubi J, Zapata-Serpa D, Rodriguez-Morales AJ. Dengue, chikungunya and Zika co-infection in a patient from Colombia.J Infect Public Health. 2016. pii: S1876-0341(15)00221-X. http://dx.doi. org/10.1016/j.jiph.2015.12.002

23. Pan American Health Organization (PAHO), World Health Organization (WHO) Regional Office for the Americas. Information for healthcare providers on chikungunya fever. Washington: PAHO/WHO; 2014. Available from: http://www. paho.org/hq/index.php?option=com_docman\&task=doc_down load\&Itemid $=270 \&$ gid $=23974$ \&lang=en

24. Hoz JM, Bayona B, Viloria S, Accini JL, Juan-Vergara HS, Viasus D. Fatal cases of Chikungunya virus infection in Colombia: Diagnostic and treatment challenges.J Clin Virol. 2015;69:27-9. DOI: 10.1016/j.jcv.2015.05.021 PMID: 26209372

25. Torres JR, Castro JS, Rodríguez L, Saravia V, Arvelaez J, RíosFabra A, et al. , Leopoldo Códova G. Chikungunya fever: Atypical and lethal cases in the Western hemisphere: a Venezuelan experience.IDCases. 2015;2(1):6-10. DOI: 10.1016/j. idcr.2014.12.002 PMID: 26793440

26. World Health Organization (WHO). Dengue: guidelines for diagnosis, treatment, prevention and control. Geneva: WHO; 2009. Available from: http://www.who.int/tdr/publications/ documents/dengue-diagnosis.pdf

27. Huerre MR, Lan NT, Marianneau P, Hue NB, Khun H, Hung NT, et al. Liver histopathology and biological correlates in five cases of fatal dengue fever in Vietnamese children. Virchows Arch. 2001;438(2):107-15.PMID: 11253111

28. Martina BE, Koraka P, Osterhaus AD. Dengue virus pathogenesis: an integrated view.Clin Microbiol Rev. 2009;22(4):564-81. DOI: 10.1128/CMR.00035-09 PMID: 19822889

29. Das T, Jaffar-Bandjee MC, Hoarau JJ, Krejbich Trotot P, Denizot $M$, Lee-Pat-Yuen $G$, et al. Chikungunya fever: CNS infection and pathologies of a re-emerging arbovirus. Prog Neurobiol.
2010;91(2):121-9. DOI: 10.1016/j.pneurobio.2009.12.006 PMID: 20026374

30. Saswat T, Kumar A, Kumar S, Mamidi P, Muduli S, Debata NK, et al. High rates of co-infection of Dengue and Chikungunya virus in Odisha and Maharashtra, India during 2013. Infect Genet Evol. 2015;35:134-41. DOI: 10.1016/j.meegid.2015.08.006 PMID: 26247719

31. Parreira R, Centeno-Lima S, Lopes A, Portugal-Calisto $D$, Constantino A, Nina J. Dengue virus serotype 4 and chikungunya virus coinfection in a traveller returning from Luanda, Angola, January 2014. Euro Surveill. 2014;19(10):20730. DOI: 10.2807/1560-7917. ES2014.19.10.20730 PMID: 24650864

32. Lanciotti RS, Valadere AM. Transcontinental movement of Asian genotype chikungunya virus. Emerg Infect Dis. 2014;20(8):1400-2. DOI: 10.3201/eid2008.140268 PMID: 25076384

33. Leparc-Goffart I, Nougairede A, Cassadou S, Prat C, de Lamballerie X. Chikungunya in the Americas.Lancet. 2014;383(9916):514. DOI: 10.1016/S0140-6736(14)60185-9 PMID: 24506907

34. Teixeira MG, Andrade AM, Costa MC, Castro JN, Oliveira FL, Goes CS, et al. East/Central/South African genotype chikungunya virus, Brazil, 2014. Emerg Infect Dis. 2015;21(5):906-7. DOI: 10.3201/eid2105.141727 PMID: 25898939

\section{License and copyright}

This is an open-access article distributed under the terms of the Creative Commons Attribution (CC BY 4.0) Licence. You may share and adapt the material, but must give appropriate credit to the source, provide a link to the licence, and indicate if changes were made.

This article is copyright of the authors, 2016. 